\title{
Analysis of the Volume, Value and Conversion Performance of a National Destination Marketing System Website.
}

\author{
Patrick Horan \\ Technological University Dublin, patrick.horan@tudublin.ie \\ P McCarthy \\ Queen Margaret College, Edinburgh \\ Andrew Frew \\ Queen Margaret College, Edinburgh
}

Follow this and additional works at: https://arrow.tudublin.ie/tfschmtcon

Part of the E-Commerce Commons, and the Technology and Innovation Commons

\section{Recommended Citation \\ Horan, Patrick; McCarthy, P; and Frew, Andrew, "Analysis of the Volume, Value and Conversion Performance of a National Destination Marketing System Website." (2002). Conference papers. 13. https://arrow.tudublin.ie/tfschmtcon/13}

This Conference Paper is brought to you for free and open access by the School of Tourism \& Hospitality Management at ARROW@TU Dublin. It has been accepted for inclusion in Conference papers by an authorized administrator of ARROW@TU Dublin. For more information, please contact arrow.admin@tudublin.ie, aisling.coyne@tudublin.ie,gerard.connolly@tudublin.ie.

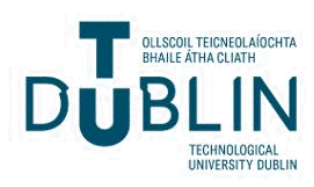




\title{
Analysis of the Volume, Value and Conversion Perform- ance of a National Destination Marketing System Web- site
}

\author{
${ }^{a}$ Andrew J Frew, \\ ${ }^{\text {a }}$ Peter J McCarthy, and \\ ${ }^{\mathrm{b}}$ Patrick Horan \\ ${ }^{a}$ The Scottish International Tourism Institute \\ Queen Margaret University College, UK \\ \{afrew, pmccarthy\}@qmuc.ac.uk \\ ${ }^{\mathrm{b}}$ School of Hospitality and Tourism \\ Dublin Institute of Technology, Ireland \\ phoran@dit.ie
}

\begin{abstract}
In 1998, the Scottish Tourist Board sought to 'develop a 'real time' database covering all tourism products and services throughout Scotland through visitscotland.com'. Since then over $£ 3 \mathrm{~m}$ has been invested in this project with some 15,000 businesses and 17,500 products covering the whole spectrum of tourism business now searchable through the Web. The claim has been that there would be an increase in business being generated, initially with bookings through the more traditional channels such as telephone, fax, mail as well as e-mail and the there has also been the anticipation that the official national tourist board website would generate significant additional business. There have been little data to substantiate this viewpoint and this study sought to establish a methodology to derive preliminary baseline performance data in terms of tourism volumes, values and look-to-book ratios. The analysis provides tourism volume, value and conversion ratios which are compared with others available in the sector. The outcomes will be of interest to those concerned with the performance of tourism websites in general and destination-defined websites such as DMS.
\end{abstract}

Keywords: tourism; electronic distribution; web conversion, DMS

\section{Introduction}

One of the critical areas in this research is an examination of the look-to-book ratios, a term used (indiscriminately) in ecommerce to differentiate between 'unique visitors' to a website, who don't purchase anything, and those unique visitors who do actually buy online. Expressed as a ratio (or \%), this has emerged as an important, but illdefined, indicator for ecommerce enterprises, with conversion rates now a key ecommerce operating metric. This study used specific 'server requests for a unique product identification (ID)' as the core looker statistic. Recent ecommerce conversion rates include; southwest.com $(9.1 \%)$, amazon.com $(8.6 \%)$, hallmark.com $(7.5 \%)$, 
CDNow (6.8\%), beyond.com (6.6\%). Note these are, in the terms of this paper, online conversion ratios, a sub-set of Indirect Booking. It should be remembered that these are channels where online purchase is almost the only option and thus have high ratios compared with channels that have multiple offline options. A more appropriate comparison in the tourism sector may come from DMS such as Gulliver or Tiscover. Ratios vary according to factors such as the nature of the website, or where people are in the buying cycle when they visit the website (Ecommerce News, 1999). For example, according to a study conducted by Shop.org and Boston Consulting Group in April 2000 (HK Interface Design, 2000), lookers were generally being converted at a rate of $1.8 \%$. Another high profile ecommerce enterprise is Travelocity.com. According to their second quarter figures from the year 2000, sales conversion rate was running at $6.9 \%$, which compared with a rate of $2.8 \%$ for the same quarter in 1999, and 4.7\% for the first quarter of 2000 (Travelocity.com, 2000). An example of conversion rates from a European based travel operation is that of Travel24.comAG, which has posted a conversion rate of $1.4 \%$ (Moser, 2000). The travel industry is believed to have the biggest gap between lookers and bookers, (Gilbertson, 1999) and there is evidence to suggest it is growing (Levin, 2000). Solutions to improve sales conversion ratios are being acted upon by the ecommerce industry in all sectors fa major example being enhanced credit card security (Chadwick Martin Bailey, Travel Weekly 20/3/00, in Nelson, 2000). Another key issue is the user interface, with websites continually being made faster and more easily navigable (Gilbertson, 1999). Indeed, Rourke (2001) contends that in the ecommerce environment a Darwinistic "survival of the easiest" is occurring. Forrester Research (2001) estimates that worldwide ecommerce is about to reach hyper-growth, (\$6.8 trillion by 2004) and the European online travel market is also predicted to grow strongly, currently estimated to be the largest consumer ecommerce sector in Europe, with a (travel) market share of 30\% in 2001 (Jupiter MMXI, 2001). While the data herein is primarily U.S. based, it is interesting to note that in fact the U.K. has been found to have the highest percentage of home Internet users visiting an ecommerce site (Pastore, 2001). In recent years there has been specific relevant research work (Frew and O'Connor, 1998-2000) conducted into successful performance criteria for DMS and many other authors have explored aspects of DMS operation. The current work looks at the development of a methodology to derive volumes, values and conversion ratios for a national DMS and thus provides a useful complement to this earlier work.

\section{Aim}

The primary aim of this study was to establish a methodology to measure the volume and value of the business arising from the accommodation sector in Scotland generated through, or in some way mediated by, the official national tourist board (VisitScotland) website; http://www.visitscotland.com.

\section{$3 \quad$ Methodology}


Due to its size and importance as an economic indicator, the research focused on the accommodation sector. Of the 10,781 accommodation businesses listed on http://www.visitscotland.com at the time of the research only 235 had the ability, through the website, to accept, confirm and charge a deposit for bookings using full online transaction. The vast majority of the other accommodation providers accepted bookings using the telephone, fax, letter, email or in a variety of intermediated ways such as travel agents and other websites. The approach was based upon two interconnected tiers. The first was an extensive survey of accommodation providers undertaken by a variety of routes; a postal questionnaire was sent to 1200 recipients, supplemented by fax, email and web survey delivery to a further 4000 randomly selected recipients drawn from the visitscotland.com database. This tier provided self-reported data that formed the basis for the calculation of the volumes, values and also a direct (to property) conversion ratio, by allowing a correspondence to be derived between the reported activity and the property-specific activity on the server. The second tier of research was based upon an in-depth log file analysis of the VisitScotland website focusing on full-transaction online booking and thus giving data on volumes, values and an indirect conversion ratio.

\section{Results}

Results from the 434 respondents to the survey encompass a range of marketing methods and associated marketing spend, range of online reservation resources employed and in particular the use of visitscotland.com. Respondents were asked detailed questions about their own web presence. The volume of bookings and guests through each channel was assessed as was the perceived impact of the visitscotland.com website, however, only a limited presentation of the findings is possible within the scope of the current paper. The survey itself provided substantial background on approaches to marketing, but more importantly it elicited self-reported data on levels of business over an extended period, essential for direct conversion assessment. In order to explore both direct and indirect conversion ratios it was necessary to examine the performance of the VisitScotland website through an analysis of the server log files for the period January 2000 to February 2001.

\subsection{Survey}

Figure 1 below indicates the primary means used by respondents in marketing their business. Perhaps a little surprisingly a significant percentage - just over two-thirds of respondents indicated that their own website was a major marketing channel, ranking third in overall importance. Figure 2 illustrates the range of website representation - representation on the VisitScotland website came fifth with just under twothirds. Respondents identified a wide range of electronic channels which they used including; regional websites (39\%), VisitScotland (70\%), own property website $(62 \%)$, hotel central reservations system (18\%) - largely the chains and consortia, global distribution systems (10\%), web-based intermediaries (15\%), and bidding site $(5 \%)$. 


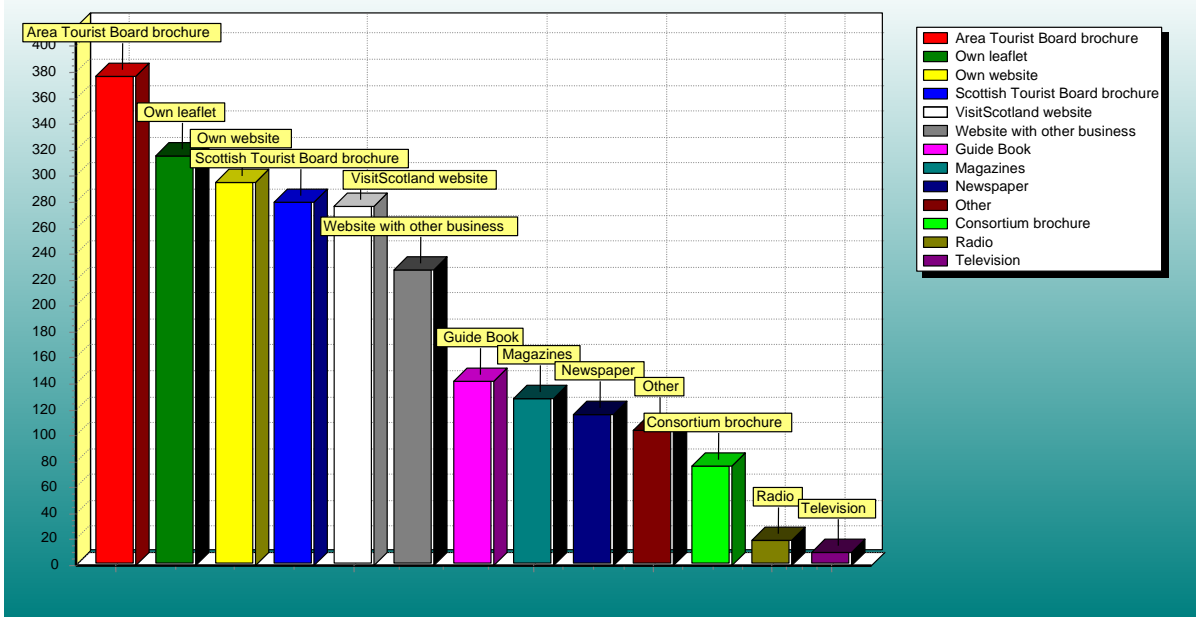

Figure 1 Marketing Methods

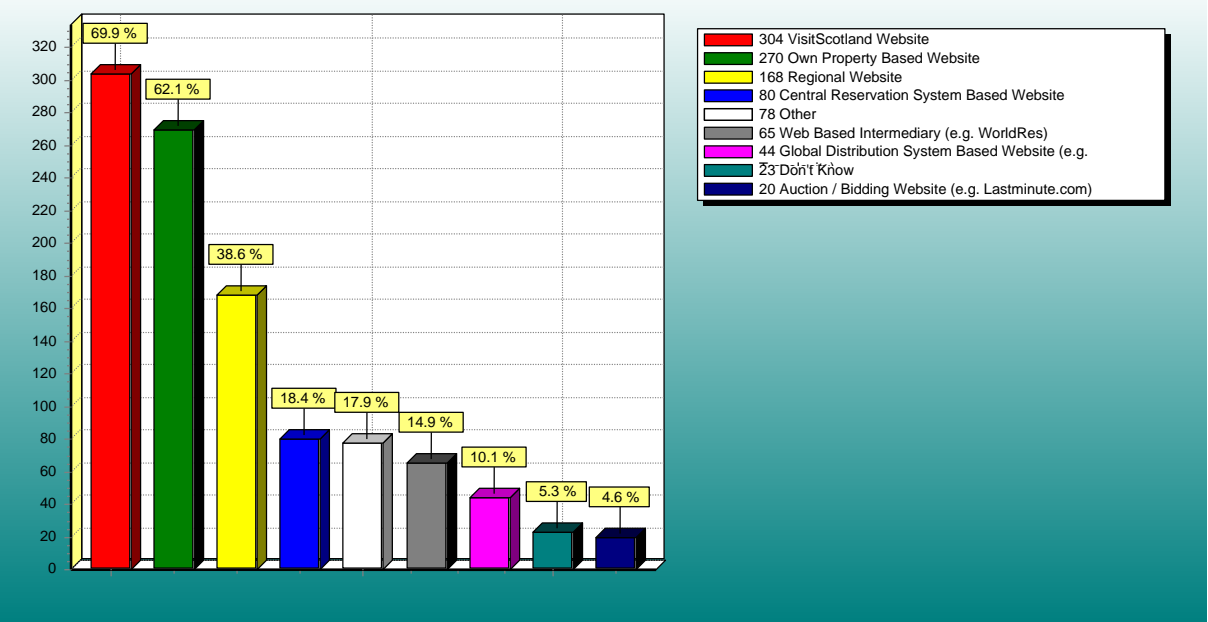

Figure 2 Representation through Websites

Nearly $40 \%$ of respondents indicated that they received between $1-29 \%$ of their business indirectly through VisitScotland's web activities. A significant $4 \%$ of respondents claimed to receive $30-59 \%$ of business this way.

\subsection{Volumes and Values}

A key element of the survey was to assess the extent to which visitscotland.com played some part in the bookings process, either directly or indirectly. For the pur- 
poses of this research, online bookings $\left(\mathbf{I}_{\mathbf{O}}\right)$ are taken to be those made entirely online through the visitscotland.com website. Indirect bookings (I) are all bookings which at some point have touched the visitscotland.com website whether they were online, or ultimately came via letter, phone, fax, email etc ( $\mathbf{I}_{\mathbf{O}}, \mathbf{I}_{\mathbf{L}}, \mathbf{I}_{\mathbf{P}}, \mathbf{I}_{\mathbf{F}}, \mathbf{I}_{\mathbf{E}}$ and so on). Direct bookings are all others made through and with the accommodation provider, including the use of any other intermediary, i.e. at no point were mediated by the visitscotland.com website. It should be stated at the outset that there is no direct attempt to establish a causal link between visitscotland.com and indirect bookings and to go beyond broad inference would require an in-depth demand-side survey to identify the specific precursors to consumer choice.

\subsubsection{All Bookings}

According to the respondents there was a total of 139,358 bookings made over the 14-month period covered by the study resulting in $\mathbf{3 6 5 , 4 4 9}$ guests $(342,087$ actual guests in 12 months). In previously conducted research by the tourist board, VisitScotland had provided a figure of $\mathbf{£ 2 2 4}$ as the average spend per person per trip as the overall value of each guest, thus representing when multiplied up by the reported guest population, a total spend (not just in the accommodation sector) of $£ 81.8 \mathrm{M}$. Over the Calendar year 2000 this becomes $£ 76.6 \mathrm{M}$ and if extrapolated to the full population of 10,781 accommodation providers, produces an estimated figure of $£ 1.903 \mathrm{M}$ as shown below:

$$
\begin{aligned}
& \mathbf{A} \mathbf{V}_{\mathbf{S}}=\text { All Bookings from the Sample }=342,087 \mathrm{X} £ 224=\mathbf{£ 7 6 . 6 \mathbf { M }} \\
& \mathbf{A} \mathbf{V}_{\mathbf{P}}=\text { Projected Bookings from the Population }=342,087 \mathrm{X}(10,781 / 434)=\mathfrak{£ 1 , 9 0 3 \mathbf { M }}
\end{aligned}
$$

In other words the self-reported guest levels generated through the survey, would scale up to represent a total guest spend value of $£ 1,903 \mathrm{M}$. If $\mathbf{A V}$ is taken to be the value of all possible bookings, $\mathbf{A} \mathbf{V}_{\mathbf{S}}$ is thus the all bookings value generated in the sample and $\mathbf{A V}_{\mathbf{P}}$ may be used to represent the projected value coming from all bookings for the total population of Scottish accommodation providers on visitscotland.com.

The above picture represents one dimension - the overall reported bookings/guests offered by the respondents. Let us now look a little more closely at the influence of visitscotland.com. Respondents were invited to indicate the percentage of their business (regardless of eventual booking channel) that had used the VisitScotland website prior to booking. The ranges offered for response were 1-9\%, 10-19\%, 20-29\% etc. and, as is common practice with inferential work such as this, the mid-point of each range was taken $5 \%, 15 \%, 25 \%$ etc., as a multiplier against the reported bookings and guests to generate an estimate of actual numbers through this means. If we now look at the actual level of business generated which at some point has been intermediated by visitscotland.com, in other words the indirect bookings, I, this produces a selfreported figure of 6,634 guests across the 14-month period covered by the study and 
across the period January - December 2000; 6,157 guests. Using the same basis for calculation as above, this level of activity may be inferred to produce $\mathbf{f 1 . 3 8 M}$ in guest value from the survey sample. Again, if we use 10,781 as our population, this would scale to $\mathbf{2 3 4 . 3 M}$ for the overall value of indirect bookings (i.e. mediated in some manner by visitscotland.com).

$$
\begin{aligned}
& \mathbf{I V} \text { S Indirect Value for the Sample }=\mathbf{£ 1 . 3 8 M} \\
& \mathbf{I V}_{\mathbf{P}}=\text { Indirect Value projected for the Population }=\mathbf{f 3 4 . 3 M}
\end{aligned}
$$

\subsubsection{Online Bookings}

Online bookings are a subset of all indirect bookings (I) and are in effect equivalent to Io.

The data for online bookings derived from visitscotland.com came from the period July $28^{\text {th }} 2000$ to May $9^{\text {th }} 2001$, where there were available and valid log files. There were 115 bookings made covering 194 bed nights, total transactions spend of $\mathfrak{1 1 1 , 6 1 9}$ and an average transaction spend per booking of $\mathfrak{£ 1 0 1}$. These bookings were made with only 59 (of a possible 235) separate accommodation providers. If we take as a guideline the ratio of bookings to guests derived from our survey, we arrive at a figure of approximately 2.6. Using this figure and the previously applied $£ 224$ as the spend per guest generates a guest value from online bookings of $115 \times £ 224 \times 2.6=\mathfrak{£ 6 6 , 9 7 6}$ for this period and an approximate $12 / 9.5$ for a projected full year $\mathbf{E 8 4 , 6 0 1}$. Anything beyond this is speculation based on a very limited data set, however, for interest the value of online bookings has been projected based on a $25 \%$ participation rate, an average of 10 bookings per property per year and holding the average spend constant giving $\left(\mathbf{I}_{\mathbf{O}} \mathbf{V}_{\mathbf{P}}\right)$.

$$
\begin{aligned}
& \mathbf{I}_{\mathbf{O}} \mathbf{V}_{\mathbf{S}}=\text { Online Value for the Sample (full year estimate) }=\mathbf{\$ 8 4 , 6 0 1} \\
& \mathbf{I}_{\mathbf{O}} \mathbf{V}_{\mathbf{P}}=\text { Online Value projected for the Population }=\mathbf{£ 1 4 , 5 6 0 , 0 0 0}
\end{aligned}
$$

\subsection{Conversion Ratios}

The calculation of the indirect bookings conversion ratio (ICR) yields a ratio of $7.35 \%$. This involves taking the total number of bookings reported through visitscotland.com per accommodation provider and dividing these by the total number of server requests for the equivalent ID over the 14-month period. 
The overall online booking conversion ratio (OCR) calculation data takes the average of each monthly conversion percentage for each provider summed and then averaged across all providers. This calculation produces a figure of $1.23 \%$ for online bookings. At this early stage in development (of the ecommerce aspects of the website), one should not attach too high a regard to the actual conversion ratio in terms of any financial projections since it is the absolute online bookings transaction volume that is vitally important and these are at present low. In due course as the system and market matures, increasingly robust measures of online conversion will evolve from this baseline and provide a useful as a measure of effectiveness. The detailed algorithms used for calculation are generalisable to any Destination Marketing/Management System (DMS) and may be applied broadly within tourism ecommerce.

It is perhaps appropriate at this point to place in context the Austrian-based Tiscover system, which is generally regarded as one of the more mature DMS. This has consistently demonstrated significant growth and strong overall performance characteristics in recent years. The following data represent some key indicators for the system:

Table 2 Tiscover transaction activity

$\begin{array}{lrrr} & \mathbf{1 9 9 7} & \mathbf{1 9 9 9} & \mathbf{2 0 0 1} \text { (est) } \\ \text { Pageviews } & & & \\ \text { Visits } & 3,600,000 & 39,200,000 & 275,000,000 \\ \text { Booking and Reservation Transactions } & 1,500,000 & 13,800,000 & 60,000,000 \\ & 23,500 & 243,000 & 1,200,000\end{array}$

Published look to book ratio is $55: 1$, i.e. $\mathbf{1 . 8 \%}$

Anecdotally, Stewart Stephens, Managing Director of Gulliver Infores, also kindly offered the following observation on the activities of over a dozen websites which the core booking engine services:-

"the number of people clicking through to the booking site and the proportion that subsequently book ...ranges from 1\% to $2.5 \%$...the highest conversion ratio is on the Irish Tourist Board website and the lowest on a richcontent site"

Taken together, these may offer useful comparators when considering the outcomes of this study.

\section{Conclusions and Recommendations}


The two main means of booking accommodation listed in visitscotland.com were considered as either bookings online via the visitscotland.com website or indirect bookings through any other means. In looking at the first of these, a procedure has been established to examine the visitscotland.com server log files and map server request activity onto actual bookings. This procedure is straightforward and the only significant caveat applies to the volume of properties that are bookable online and consequent small transaction volumes. It is therefore relatively simple to monitor volumes and values but the robustness of the online booking conversion ratio $(1.23 \%)$ is open to challenge. Extension and growth of the product activity on visitscotland.com will progressively strengthen the credibility of the online conversion ratio and in due course should allow for trend analysis - future research will address this.

Indirect bookings, in other words all bookings which respondents identified as coming from (in some way), but not necessarily through, visitscotland.com, presented a much more complex challenge. The robustness of the methodology is dependent upon a number of factors including; the accuracy of the overall population, accuracy of selfreported data, respondent level applied and the calculation algorithm applied to the data. The respondent level used was the total respondent population since all statistics were applied at the global level although this paper provides a very limited sub-set. Self-reported data inevitably produced some extremes and in the calculations, a policy decision was made to include all data. However, if for example the extreme $1 \%$ of respondents (top and bottom) were excluded from calculation, the indirect conversion ratio falls from $7.35 \%$ to $5.46 \%$. Further 'capping' of the data to $5 \%$ produced little further change so it could be argued that a 1\% cap on extreme data would stabilise this percentage and in a future iteration of the methodology Standard Deviation bands may be applied as an appropriate means of excluding extreme data.

Overall it is argued that the methodology provides for robust volume and value data for online bookings but a conversion ratio that is as yet merely indicative. It is also argued that the volumes and values produced for direct bookings is indicative only. To improve robustness, this would require more accurate data and thus more formal data collection methods being employed by accommodation providers. This would be further strengthened by the implementation of a baseline demand-side survey. The indirect booking conversion ratio $(7.35 \%)$ would also be strengthened by the implementation of these two (data collection and survey) approaches and by additional data stabilising techniques.

The online conversion ratio $(1.23 \%)$ as it is reported above, bears comparison with other regional or national systems, however, the transaction volume base for this is very small indeed and one should be cautious in reading too much into this number at this stage. The absolute transaction volumes are well below those of comparable systems elsewhere and one could reasonably project that with more comprehensive ecommerce facilities and higher absolute volumes then the value of business conducted on or through the site would escalate substantially. At the time of writing there 
is indeed evidence emerging of just such an increase and strengthening the data, procedures and algorithms will form part of any future work.

\section{Future Work}

This paper describes the development and application of an initial methodology and has thus provided a foundation for future work in volumes and values. Further work should seek to address both the primary research dimension and the modelling process itself, to refine it and enhance its overall robustness both as a means of identifying indicator data and providing a sound basis for trend analysis. Firstly, it would be beneficial to have available larger and more robust data sets, and to this end ongoing provider and consumer survey work will be considered. It is also anticipated that future research will incorporate longitudinal work with the server log data both for online and indirect correlational studies.

In due course it should be possible to break down the data at the server side by Area, Grade, Size, Type of Property and so on and to keep an ongoing track of direct booking performance on these dimensions. This will ideally be tied to ongoing survey data to correlate the indirect booking levels and thus overall and detailed conversion ratios. The data from the web channel vis-à-vis the manual survey suggests that the web respondents should be recruited and extended for future work.

\section{Acknowledgements}

The authors are also pleased to acknowledge the full support of VisitScotland in providing data, access and a challenging research environment. Thanks are also due to Dr Stewart Stephens (Managing Director, Gulliver Infores) and Arno Ebner (Managing Director, Tiscover) for the supply of background data indicated in the text.

\section{References}

AC Nielsen (2001) 'solid Consumer confidence in the Net' www.nua.1e/surveys/index. $(28 / 6 / 01)$

Ecommerce News (1999) 'Traditional marketers catch on to ecommerce' http://sellitontheweb.com/ezine/news0281.shtml (26/6/01).

Forrester Research (2001) 'Forrester Findings Internet Commerce' www.forrester.com/ER/Press/ForrFind/0,1768,0,00.html (26/6/01)

Frew, A.J. and O'Connor, P., (1998) A Comparative Examination of the Implementation of Destination Marketing System Strategies: Scotland and Ireland, in Information and Communi- 
cations Technologies in Tourism, D. Buhalis, A.M. Tjoa, and J. Jafari, Editors. 1998, SpringerVerlag: Vienna, Austria. p. 258-267

Frew, A.J. and O'Connor P., (1999) Destination Marketing System Strategies: Refining and Extending an Assessment Framework, in Information and Communications Technologies in Tourism, D. Buhalis and W. Schertler, Editors. 1999, Springer-Verlag: Vienna, Austria. p. 398407

Frew, A.J. and O'Connor, P., (1999) Destination Marketing System Strategies in Scotland and Ireland: An Approach to Assessment. Information Technology and Tourism, 1999. 2(1): p. 213

Gilbertson, D. (1999) 'Turning Lookers into Bookers' in The Arizona Republic, December 10, 1999. available: www.asiamaya.com/travel-asia/12_10_99_stories/turning.htm (26/6/01)

HK Interface Design (2000) 'How to Turn Lookers into Bookers' www.hkid.org/lookers-tobookers.html (25/6/01)

Jupiter MMXI (2001) 'European online travel market set for strong growth' http://production.investis.com/ebookers/background (29/6/01)

Levin, A (2000) 'Automated Information Exchange in the Online Travel Market' (June 13, 2000) www.fastwater.com/Library/General/online-travel/OnlineTravel-fr.php3 (25/6/01). McQuivey, J. (1999) 'Q\&A with James McQuivey: Online Travel: Turning Lookers into Bookers' in Business Week Online:Business Week ebiz (July 27, 1999)

www.businessweek.com/technology/content/9907/727mcquivey.htm (25/6/01)

Moser, M. (2000) 'Equity Research Report Travel24.com AG 21 February 2000' available: www.travel24.com/investorrelations/ir/an (26/6/01)

Nelson, L. (2000) 'Air Travel on the Internet - What Aren't The Internet Travelers Booking Online?’: http://airtravel.about.com/travel/airtravel/library/weekly/aa041300.htm (25/6/01)

O'Connor, P and Frew A.J. (2000) Evaluating Electronic Channels of Distribution in the Hotel Sector, in, Information and Communications Technologies in Tourism, D.Fesenmaeir, Editor, Springer-Verlag: Vienna, Austria, -p324-335

O'Connor, P. and Frew, A.J., (2000) Critical Issues in Destination Management System Development, Implementation and Operation, Tourism Destination Marketing, J. Ruddy and S Flanagan, Editors, p559-566

Pastore, M. (2001) 'UK Users Most Likely to Visit Ecommerce Sites':

http://cyberatlas.internet.com/big picture/geographics/print/0,5911 791021,00.html (28/6/01) Rourke, C. (2001) 'There's an art to turning your web lookers into bookers' in Scottish Computer Headline ( February 2001), www.uservision.co.uk/Articles/SCHarticle.html (26/6/01) Travelocity.com (2000) Press Release, 19 July 2000 'Travelocity.com Reports Record Second Quarter Financial Results',:

http://svc.travelocity.com/pressroom/pressrelease/0,1090,1229\TCYCA (26/6/01) 